\title{
Persistent Pain Facilitates Response to Morphine Reward by Downregulation of Central Amygdala GABAergic Function
}

\author{
Zhi Zhang*, ${ }^{*}$, Wenjuan Tao ${ }^{2}$, Yuan-Yuan Hou', Wei Wang', Yun-Gang Lu ${ }^{3}$ and Zhizhong Z Pan*,' \\ 'Department of Anesthesiology and Pain Medicine, University of Texas MD Anderson Cancer Center, Houston, TX, USA; ${ }^{2}$ Department of \\ Neurobiology and Biophysics, Key Laboratory of Brain Functions and Diseases, School of Life Science, University of Science and Technology of China, \\ Hefei, China; ${ }^{3}$ Department of Integrative Biology and Pharmacology, University of Texas Health Science Center at Houston, Houston, TX, USA
}

\begin{abstract}
Opioid-based analgesics are widely used for treating chronic pain, but opioids are highly addictive when repeatedly used because of their strong rewarding effects. In recent years, abuse of prescription opioids has dramatically increased, including incidences of misuse of opioid drugs prescribed for pain control. Despite this issue in current clinical pain management, it remains unknown how pain influences the abuse liability of prescription opioids. Pain as aversive experience may affect opioid reward of positive emotion through common brain sites involved in emotion processing. In this study, on a rat model of chronic pain, we determined how persistent pain altered behavioral responses to morphine reward measured by the paradigm of unbiased conditioned place preference (CPP), focusing on GABAergic synaptic activity in neurons of the central nucleus of the amygdala $(\mathrm{CeA})$, an important brain region for emotional processing of both pain and reward. We found that pain reduced the minimum number of morphine-conditioning sessions required for inducing CPP behavior. Both pain and morphine conditioning that elicited CPP inhibited GABA synaptic transmission in CeA neurons. Pharmacological activation of $\mathrm{CeA} \mathrm{GABA}_{A}$ receptors reduced the pain and inhibited CPP induced both by an effective dose of morphine and by a sub-threshold dose of morphine under pain condition. Furthermore, inhibition of $\mathrm{CeA} \mathrm{GABA}_{\mathrm{A}}$ receptors mimicked the pain effect, rendering the subthreshold dose of morphine effective in CPP induction. These findings suggest that pain facilitates behavioral responses to morphine reward by predisposing the inhibitory GABA function in the CeA circuitry involved in the behavior of opioid reward.

Neuropsychopharmacology (2014) 39, 2263-227I; doi:I0.1038/npp.2014.77; published online 23 April 2014
\end{abstract}

\section{INTRODUCTION}

Opioids such as morphine and its derivatives have been the mainstay of therapies for clinical pain control over the past decades. Although opioids are highly effective for pain inhibition, they are known to induce severely aversive side effects, including analgesic tolerance, physical dependence, and opioid addiction (Ballantyne and LaForge, 2007; Bhargava, 1994; Woolf and Hashmi, 2004). Opioid addiction is a chronic psychiatric disease and is pharmacologically driven partly by the strong rewarding effects of opioids. Concerns about the risk of opioid abuse significantly hamper their optimal use in treatment of chronic pain conditions. In fact, incidences of prescription opioid abuse have been considerably increased in recent years and the risk of developing prescription opioid abuse may be underestimated (Boscarino et al, 2010; Edlund et al, 2010;

\footnotetext{
*Correspondence: Dr Z Zhang, Key Laboratory of Brain Functions and Diseases, School of Life Science, University of Science and Technology of China, Hefei 230027, China. E-mail: zhizhang@ustc.edu.cn or Dr ZZ Pan, Department of Anesthesiology and Pain Medicine, University of Texas MD Anderson Cancer Center, 1515 Holcombe Boulevard, Unit II0, Houston, TX 77030, USA, Tel: +7I3 7925559 , Fax: +7I3 745 3040, E-mail: zzpan@mdanderson.org Received II November 2013; revised 21 March 2014; accepted 25 March 2014; accepted article preview online I April 2014
}

McCabe et al, 2008). Opioid analgesics are among the most frequently abused drugs (Johnston et al, 2004) and epidemiological surveys have shown increased risk of abuse of opioid analgesics in patients with chronic pain (Compton and Volkow, 2006; Sullivan and Ferrell, 2005). Although clinical studies have implicated that the reinforcing effect of opioids differs in different chronic pain states (Banta-Green et al, 2010; Kahan et al, 2006; Pohl and Smith, 2012), it is still unknown how pain may alter the rewarding properties of opioids and consequently the risk of opioid abuse in treatment of chronic pain with opioids.

The amygdala is a key brain structure that regulates emotional responses to negative and positive stimuli. The central nucleus of the amygdala ( $\mathrm{CeA})$, as the major output of amygdalar nuclei, is important in regulation of the emotional aspects of chronic pain (Fields, 2000; Neugebauer et al, 2004). It also has a critical role in the learning process of stimulus-reward association (Baxter and Murray, 2002; Bie et al, 2012; Gottfried et al, 2003; Le Merrer et al, 2009). Thus, CeA converges emotional stimuli associated with chronic pain and addictive opioids, providing an appropriate neural system to investigate interactions between pain and opioid reward. Central synaptic transmission is a main target of abused drugs and drug-induced synaptic plasticity, which outlasts the presence of drugs in the brain, has been critically implicated in the mechanisms for drug 
reward and addiction (Koob and Volkow, 2010; Luscher and Malenka, 2011; Russo et al, 2010).

In the present study on a rat model of chronic pain, we examined the effect of pain on behavioral responses to morphine reward, focusing on GABA synaptic function in CeA, which consists of 95\% GABAergic neurons (McDonald, 1982). Pharmacological manipulations of CeA GABAergic transmission were used to assess their effects on the behavior of morphine reward measured by the paradigm of conditioned place preference (CPP), an established rodent model of drug reward (Tzschentke, 2007).

\section{MATERIALS AND METHODS}

\section{Animals and the Model of Chronic Pain}

Male Wistar rats weighing 200-300g were used in all experiments. Persistent inflammatory pain was induced by a single injection of complete Freund's adjuvant (CFA, $40 \mu \mathrm{l}$ ) into a hindpaw of the rat under brief isoflurane anesthesia. All procedures involving the use of animals conformed to the guidelines by the Institutional Animal Care and Use Committees of the University of Texas MD Anderson Cancer Center and the University of Science and Technology of China.

\section{Paw-Withdrawal Test and Microinjection}

Pain threshold in a freely moving rat was measured every 5 min by the paw-withdrawal test with a Hargreaves apparatus (Stoelting, Kiel, WI). The heat intensity of stimuli was set to obtain stable baseline latencies with a cutoff time of $12 \mathrm{~s}$. CeA microinjection was performed as described previously (Bie et al, 2012; Zhu et al, 2007). Briefly, a rat was implanted with a $26-\mathrm{G}$ single-guide cannula (Plastics One, Roanoke, VA) aimed at CeA on both sides of the brain (anteroposterior, $-2.3 \mathrm{~mm}$; lateral, $\pm 4 \mathrm{~mm}$; dorsoventral, $-8.0 \mathrm{~mm}$ ). Drugs were microinjected into CeA in a volume of $1 \mu \mathrm{l} /$ side through a 33-G injector with an infusion pump at a rate of $0.2 \mu \mathrm{l} / \mathrm{min}$. All CeA microinjection sites were histologically verified after the experiment by injecting a blue dye and controls of off-site injections were performed as described previously (Bie et al, 2009). The effect of microinjected muscimol on rat CPP behavior was analyzed 10-20 min after its administration. The exact diffusion area of microinjected drugs was not determined; thus, a role of brain areas surrounding the targeted CeA cannot be completely excluded in these microinjection experiments.

\section{CPP}

The CPP paradigm was used with a three-chamber CPP apparatus (MED Associates, St Albans, VT) consisting of two test chambers (a black chamber with a stainless steel rod grid floor and a white chamber with a stainless steel mesh floor) and a central connecting gray chamber. The general CPP procedure has been described in our previous reports (Bie et al, 2012; Bie et al, 2009; Zhu et al, 2007). The conditioning procedure consisted of four phases and lasted for 7 consecutive days. Phase 1 (habituation, days 1 and 2): after an i.p. injection of saline, a rat was placed in the central gray chamber and allowed to move freely among the three chambers for 30 min each day. Phase 2 (pretest, day 3): after a saline injections (i.p.), the rat was placed in the gray chamber and a pretest was conducted for $15 \mathrm{~min}$ to determine baseline preference by recording the time spent in each chamber. Rats that spent more than $60 \%$ of the test time in any one chamber were considered biased and were excluded from the results ( $<10 \%$ of all animals). Chamber pairing of different groups was alternated to adjust for remaining chamber bias. Phase 3 (morphine/saline conditioning, days 4-6): rats were randomly assigned to morphine group and saline group as control. The rat in morphine group was injected with saline (i.p.) and immediately confined to one test chamber in the morning for $30 \mathrm{~min}$ and then injected with morphine $(3 \mathrm{mg} / \mathrm{kg}$, i.p.) and 5 min later, confined to the other test chamber for $30 \mathrm{~min}$ in the afternoon. The interval between saline and morphine conditioning was longer than $6 \mathrm{~h}$. Such a conditioning session was performed once daily for 3 days (in some experiments, four or five sessions were performed for 4 or 5 days, respectively). Phase 4 (posttest, day 7): a preference test was performed to determine morphine-induced CPP with the same procedure as that in pretest. Rats in saline group were similarly conditioned with saline only in all conditioning sessions. CPP behaviors are presented as CPP scores defined by the formula: CPP score $=$ time in morphine-paired chamber - time in saline-paired chamber in seconds. CFA or saline was injected $72 \mathrm{~h}$ before the first conditioning session. Indomethacin $(10 \mathrm{mg} / \mathrm{kg}$, i.p.) was injected $1 \mathrm{~h}$ before pretest, before posttest, or before each morphine-paring session in CFA-injected rats.

\section{Brain Slice Preparations and Whole-Cell Recordings}

The visualized whole-cell recording method has been described in our previous studies (Bie et al, 2012; Zhang et al, 2011; Zhu et al, 2007). Slices (200- $\mu \mathrm{m}$ thick) of the rat brain containing CeA were cut with a vibratome and a single slice was perfused with preheated $\left(35^{\circ} \mathrm{C}\right)$ physiological saline containing the following (in $\mathrm{mM}$ ): $126 \mathrm{NaCl}, 2.5 \mathrm{KCl}$, $1.2 \mathrm{NaH}_{2} \mathrm{PO}_{4}, 1.2 \mathrm{MgCl}_{2}, 2.4 \mathrm{CaCl}_{2}, 11$ glucose, and 25 $\mathrm{NaHCO}_{3}$ saturated with $95 \% \mathrm{O}_{2}$ and $5 \% \mathrm{CO}_{2}$, pH 7.2-7.4. Visualized whole-cell voltage-clamp recordings were obtained from identified CeA neurons with a glass pipette (resistance, 3-5 M 2 ) filled with a solution containing the following (in mM): $126 \mathrm{KCl}, 10 \mathrm{NaCl}, 1 \mathrm{MgCl}_{2}, 11$ EGTA, 10 HEPES, 2 ATP, and 0.25 GTP, pH adjusted to 7.3 with $\mathrm{KOH}$, at an osmolarity of $280-290 \mathrm{mOsM} / \mathrm{l}$. Electrical stimuli at a constant current $(0.25 \mathrm{~ms}, 0.2-0.5 \mathrm{~mA})$ were used to evoke GABA-mediated inhibitory postsynaptic currents (IPSCs). GABA IPSCs were recorded in the presence of the glutamate receptor antagonists D-(-)-2-amino-5-phosphonopentanoic acid $(50 \mu \mathrm{M})$ and 6-cyano-7-nitroquinoxaline-2,3-dione $(10 \mu \mathrm{M})$ at a holding potential of $-70 \mathrm{mV}$. Spontaneous miniature IPSCs (mIPSCs) were recorded in tetrodotoxin $(1 \mu \mathrm{M})$ and analyzed with a sliding IPSC template defined by the acquisition software program.

\section{Statistical Analyses and Materials}

Comparison of IPSC and some CPP data between two groups were made by the Student's $t$-test (unpaired or paired, two-tailed). Behavioral results of CPP with repeated 
measures were statistically analyzed by one-way or two-way ANOVA and the Bonferroni's post-hoc test. The data are presented as the mean \pm standard error of the mean (SEM). A $p$ value $<0.05$ was considered statistically significant. Drugs were purchased from Sigma-Aldrich (St Louis, MO) or Tocris Bioscience (Ellisville, MO).

\section{RESULTS}

To determine the effect of pain on response to morphine reward measured by the CPP paradigm, we compared the rate of CPP induction by morphine-conditioning sessions in rats with persistent inflammatory pain induced by an intraplantar injection of CFA and in saline-injected control rats. CFA induced persistent thermal pain sensitization (hyperalgesia), which nearly peaked on the first day and lasted for at least 9 days after CFA injection (Figure 1a). In saline-injected control rats conditioned daily with morphine at $3 \mathrm{mg} / \mathrm{kg}$ (i.p.), a minimum of five conditioning sessions was required to induce significant CPP behavior; in contrast, in CFA-injected rats, three such sessions were sufficient to induce significant CPP (Figure 1b). To determine whether this facilitating effect of pain on the preference behavior was due to morphine inhibition of CFA-induced pain, we used the non-opioid analgesic indomethacin (10 mg/kg, i.p.) to inhibit the pain. Consistent with our previous report (Zhang and Pan, 2012), indomethacin significantly inhibited CFA-induced pain sensitization (Figure 1c). With this indomethacin treatment, we found that inhibiting the pain $1 \mathrm{~h}$ before posttest had little effect on the magnitude of morphine-induced CPP in CFAinjected rats (Figure $1 \mathrm{~b}$ ). To determine potential influence of pain-induced place aversion on the CPP behavior, we treated the rats with indomethacin before morphine conditioning. Indomethacin pretreatment $1 \mathrm{~h}$ before each session of morphine paring did not significantly alter the facilitating effect of pain on CPP acquisition in CFAinjected rats (Figure 1d). Furthermore, the CPP facilitating effect of pain remained in CFA-injected rats after indomethacin pre-treatment of both saline and morphine groups before morphine conditioning, with three conditioning sessions sufficient to induce CPP (Figure 1e). These results indicate that persistent pain facilitates the acquisition of preference behavior in response to morphine reward due more likely to a facilitated rewarding effect of morphine than to morphine inhibition of pain per se.

We then determined whether persistent pain altered synaptic activities that might have contributed to the CPP facilitation, focusing on GABA synaptic transmission in
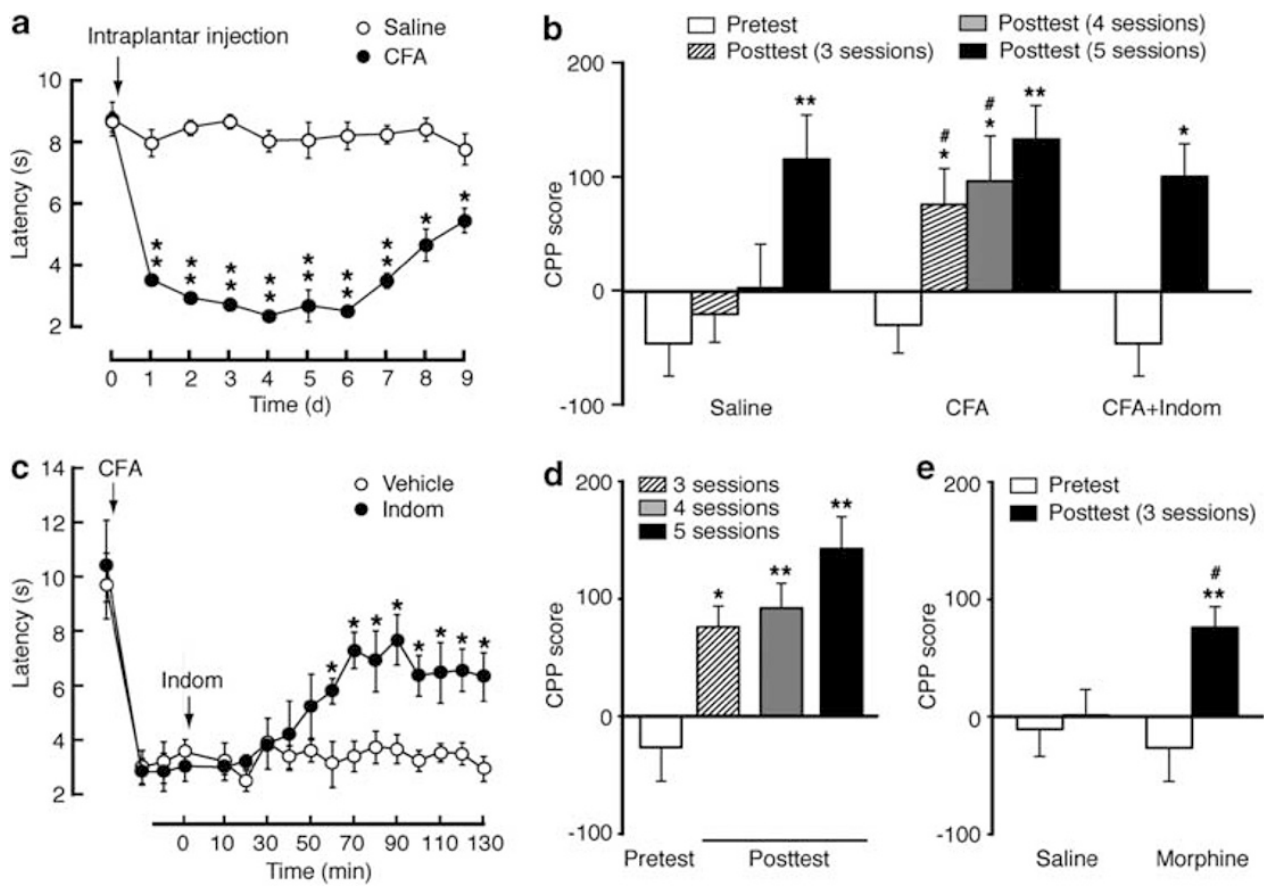

Figure I Persistent pain facilitates response to morphine reward. (a) Time course of changes in pain thresholds measured in the paw-withdrawal test after an intraplantar injection of saline or complete Freund's adjuvant (CFA) in rats (two-way ANOVA: time, $F_{(9.108)}=51.70, p<0.0001 ; C F A, F_{(1.12)}=888.5$, $p<0.000$ I; time $\times$ CFA, $F_{(9,108)}=40.74, p<0.000 I ; n=6-8$ rats). (b) Preference behaviors before (pretest) and after 3, 4, or 5 sessions of morphine conditioning (posttest) in rats with intraplantar injection of saline, CFA, or CFA plus indomethacin (Indom) injected I h before posttest (* preference compared with pretest by one-way ANOVA: saline, $F_{(3,15)}=20.2, p<0.000$ I; CFA, $F_{(3,20)}=22.62, p<0.000$ I; by paired $t$-test: $C F A+$ Indom, $t_{(1,10)}=3.728$, $p=0.0136$. " comparison between groups by two-way ANOVA: time, $F_{(3.30)}=39.5 \mathrm{I}, p<0.000 \mathrm{I} ; \mathrm{CFA}, F_{(1.10)}=4.338, p=0.0639 ;$ time $\times C F A$, $\left.F_{(3,30)}=4.958, p=0.0065 ; n=5-7\right)$. (c) Time course for changes in thermal pain thresholds after CFA injection, followed 3 days later by injection of vehicle or Indom ( $10 \mathrm{mg} / \mathrm{kg}$, i.p.) at time 0 (two-way ANOVA: time, $F_{(16,128)}=23.60, p<0.000 \mathrm{I}$; Indom, $F_{(1,8)}=16.60, p=0.0036$; time $\times$ Indom, $F_{(16,128)}=4.883$, $p=0.000 \mathrm{I}, n=5$ each group). (d) Preference behaviors in CFA-injected rats with Indom injected I h before each morphine-paring session (one-way ANOVA: $F_{(3,20)}=35.48, p<0.001, n=6$ each group). (e) Preference behaviors in CFA-injected rats after pre-treatment with Indom in both saline and morphine groups before conditioning sessions (*preference comparison within group by paired $t$-test: saline, $t_{(1,12)}=0.9840, p=0.3631 ;$ morphine, $t_{(1,10)}=4.356, p=0.0073$. \# comparison between groups by two-way ANOVA: time, $F_{(1,1)}=20.46, p=0.0009 ;$ morphine, $F_{(1,11)}=1.012, p=0.3360$; time $\times$ morphine, $\left.F_{(1,1)}=12.86, p=0.0043 ; n=6-7\right)$. ${ }_{\text {, }}, p<0.05$, *** $p<0.01$. 
CeA neurons under whole-cell voltage-clamp recordings. In control CeA slices in the presence of D-2-amino-5-phosphonopentanoic acid $(50 \mu \mathrm{M})$ and 6-cyano-7-nitroquinoxaline-2,3-dione $(10 \mu \mathrm{M})$, the evoked IPSC was completely blocked by bath application of the $\mathrm{GABA}_{\mathrm{A}}$ receptor antagonist bicuculline $(10 \mu \mathrm{M})$, confirming that it was mediated by $\mathrm{GABA}_{\mathrm{A}}$ receptors (Figure 2a). In CeA slices from CFAinjected rats 3 days after CFA injection, we found that the averaged peak amplitude of GABA IPSCs was significantly smaller when compared with control IPSCs from salineinjected rats (saline: $480.4 \pm 71.3 \mathrm{pA}, n=11$; CFA: $284.1 \pm$ $70.6 \mathrm{pA}, n=11 ; p<0.05$, Figure $2 \mathrm{~b}$ ). In the presence of tetrodotoxin $(1 \mu \mathrm{M})$, we examined the properties of mIPSCs to assess the synaptic site of this CFA-induced reduction in GABA synaptic function. In neurons from CFA-injected rats, both the frequency and amplitude of mIPSCs were significantly decreased when compared with controls (frequency: $53.2 \pm 19.4 \%$ of control, $n=16, \quad p<0.05$; amplitude: $69.9 \pm 10.9 \%$ of control, $n=16, p<0.05 ; n=21$, Figure $2 c-f$ ). These data indicate the possibility that persistent paininduced reduction in GABAergic synaptic function in CeA neurons may involve both pre- and postsynaptic sites.

Next, we assessed GABA synaptic activity in rats with morphine-induced CPP behavior. In rats after three morphine-conditioning sessions with no CPP, no difference was found in either mIPSC frequency or amplitude in CeA neurons from those of control rats conditioned with three saline sessions (frequency: $93.2 \pm 7.3 \%$ of control; amplitude: $117 \pm 12.3 \%$ of control; $n=13-16$ cells in each group, Figure $3 \mathrm{a})$. However, in rats receiving five sessions of
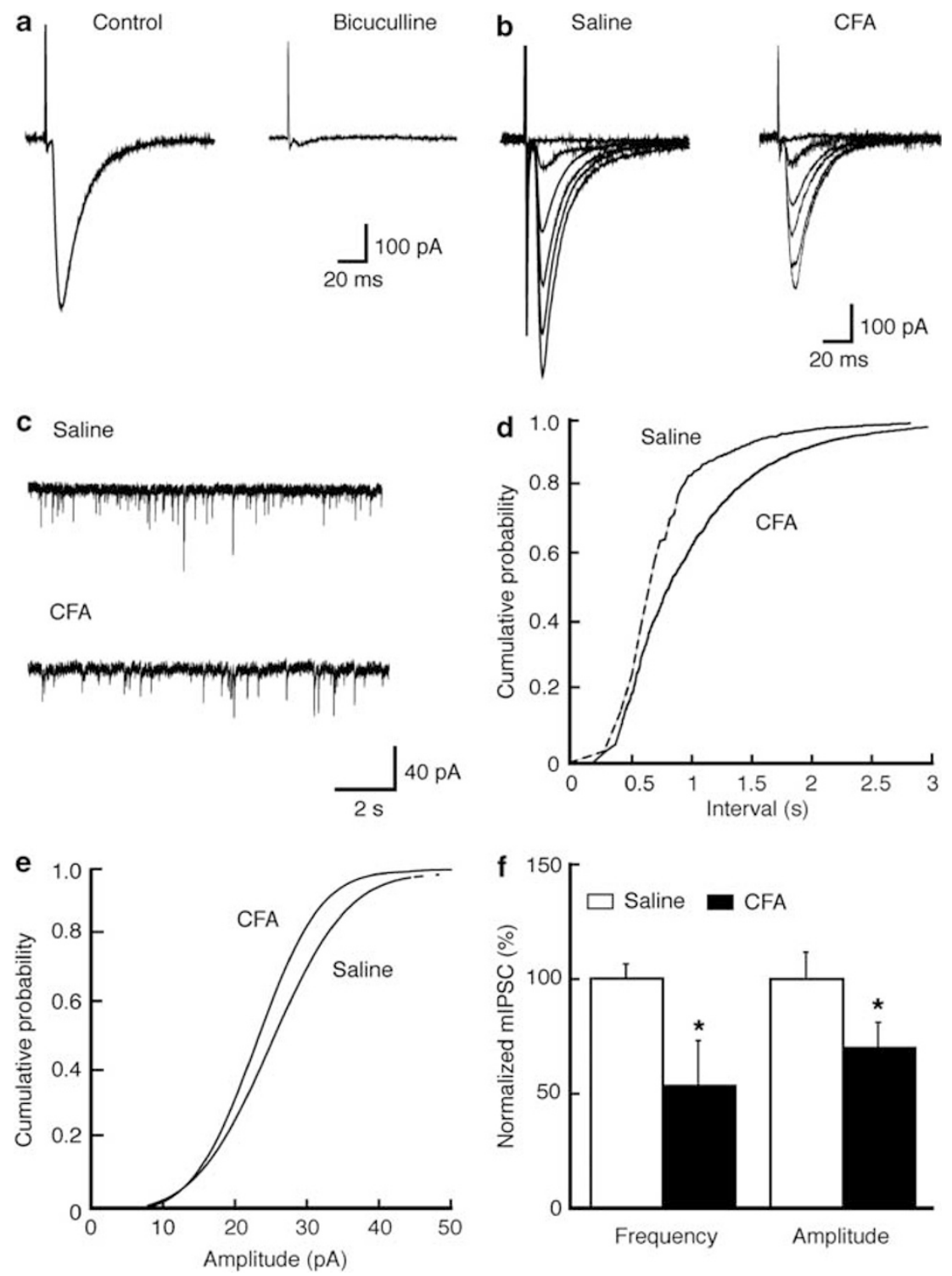

Figure 2 Persistent pain reduces GABA synaptic transmission in the central nucleus of the amygdala (CeA). (a) Representative GABAergic inhibitory postsynaptic currents (IPSCs) in a CeA neuron before (control) and during bath application of bicuculline in a slice preparation from a naïve rat. (b, c) GABA IPSCs evoked by electrical stimuli of different intensities (b) and representative current traces of miniature IPSCs (mIPSCs, c) in CeA neurons from a salineor CFA-injected rat. (d, e) Distribution graphs of mIPSC frequency (d) and amplitude (e) in CeA neurons from saline- or CFA-injected rats. (f) Summarized data of effects of CFA on mIPSC frequency and amplitude in CeA neurons. ${ }^{*} p<0.05$ (unpaired $t$-test). 
a

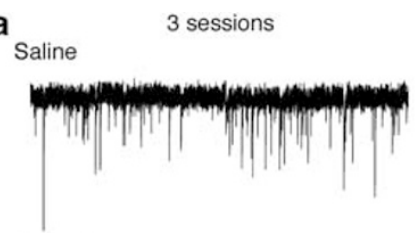

Morphine
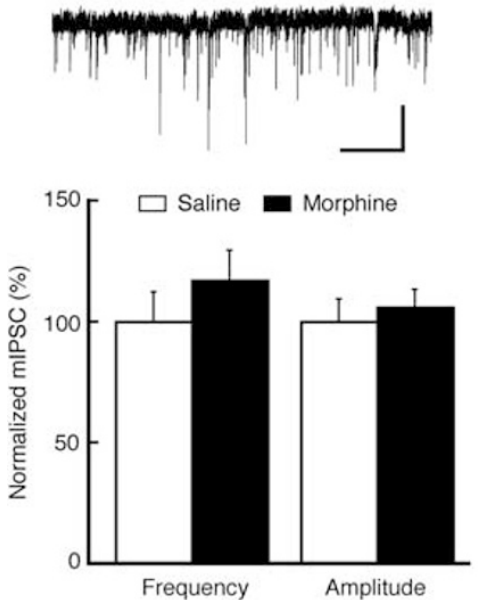

b

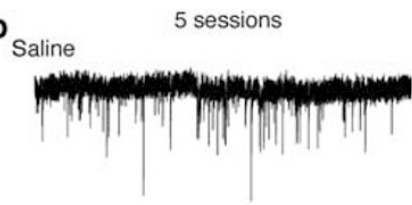

Morphine
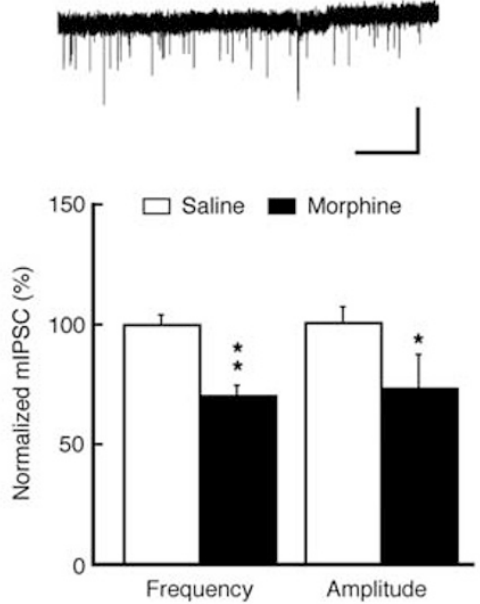

C

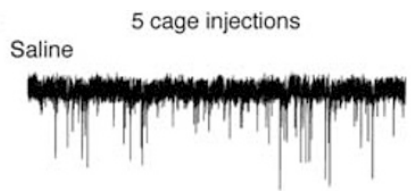

Morphine
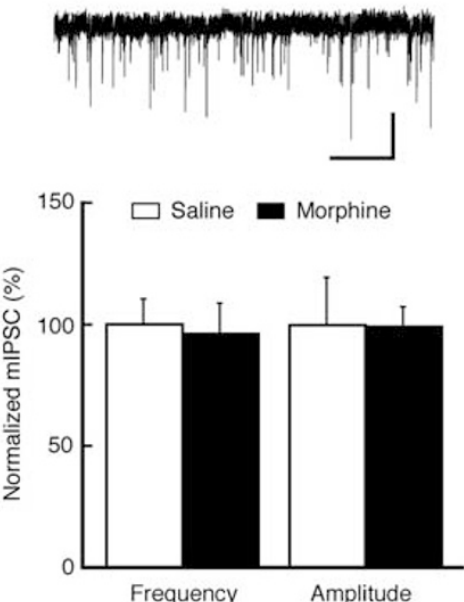

Figure 3 Morphine conditioning reduces GABA synaptic transmission in CeA. (a-c) Representative current traces of mIPSCs in CeA neurons from salineand morphine-treated rats (top) and summarized data of mIPSC frequency and amplitude (bottom) after three conditioning sessions (a), five conditioning sessions (b) and five injections in home cages (c). Scale bars $=40 \mathrm{pA}$ and $2 \mathrm{~s} .{ }^{*} p<0.05$; ${ }^{*} * p<0.0$ l (unpaired $t$-test).

morphine conditioning with CPP, both mIPSC frequency and amplitude were significantly decreased when compared with those of saline-conditioned rats (frequency: $70.3 \pm 4.3 \%$ of control, $p<0.05$; amplitude: $72.6 \pm 14.1 \%$ of control, $p<0.05 ; n=12-16$ in each group, Figure $3 b)$. In rat groups treated with the same amount of morphine in their home cages under an identical treatment paradigm, the mIPSC frequency and amplitude did not differ from those of control neurons (frequency: $96 \pm 12.3 \%$ of control; amplitude: $99.4 \pm 7.8 \%$ of control, $n=16-17$ in each group, Figure 3c). These results suggest that discriminative learning during paring of the morphine effect with novel environment may be required for the reduction in GABAergic function of $\mathrm{CeA}$ neurons.

We reasoned that if loss of GABA synaptic inhibition in CeA contributed to pain sensitization and to facilitated morphine induction of CPP, activation of $\mathrm{CeA} \mathrm{GABA}_{\mathrm{A}}$ receptors under the same conditions should inhibit the CFA and morphine effects by alleviating CFA-induced hyperalgesia and reducing morphine CPP. To test this hypothesis, we determined behavioral effects of the $\mathrm{GABA}_{\mathrm{A}}$ receptor agonist muscimol microinjected into CeA in rats in vivo. As expected, in CFA-injected rats 3 days post CFA injection, an acute, bilateral infusion of muscimol (25 ng/side) into CeA increased pain threshold in response to thermal stimuli in the paw-withdrawal test, reducing the CFA-induced pain sensitization (Figure 4a). Similar infusions of muscimol into CeA before each morphineconditioning session blocked CPP behavior induced by five morphine-conditioning sessions in rats (Figure 4b). Representative microinfusion sites in CeA were illustrated in Figure $4 \mathrm{c}$ and $\mathrm{d}$.
To further validate that $\mathrm{CeA} \mathrm{GABA}_{\mathrm{A}}$ receptors were important for the facilitating effect of pain on morphine $\mathrm{CPP}$, we examined the effect of CeA-infused muscimol on the CPP induced by sub-threshold morphine conditioning in rats with persistent pain. The sub-threshold conditioning with three morphine sessions induced significant CPP in CFA-injected rats and this CPP was inhibited by CeA infusion of muscimol (Figure 5a). Conversely, CeA infusion of the $\mathrm{GABA}_{\mathrm{A}}$ receptor antagonist bicuculline mimicked the CFA effect, as control rats with bilateral CeA infusion of bicuculline ( $25 \mathrm{ng} / \mathrm{side}$ ) before each morphine-conditioning session displayed a significant CPP behavior after three morphine-conditioning sessions (Figure 5b). Thus, it appears that persistent pain facilitates the acquisition of CPP behavior related to morphine reward by reducing GABA synaptic inhibition in CeA neurons, an effect shared by morphine in its induction of reward-related CPP behavior.

\section{DISCUSSION}

We have shown in this study that persistent inflammatory pain increases response to morphine reward in acquisition of morphine-induced CPP behavior. Our results suggest that reduction in the inhibitory function of GABAergic synapses in CeA neurons, an effect shared by persistent pain and CPP-eliciting morphine, is involved in the cellular mechanism for pain facilitation of the reward response. Thus, it is possible that persistent pain reduces the GABAergic inhibitory function in CeA neurons, predisposing the CeA circuitry for opioid induction of reward-related behavior. 

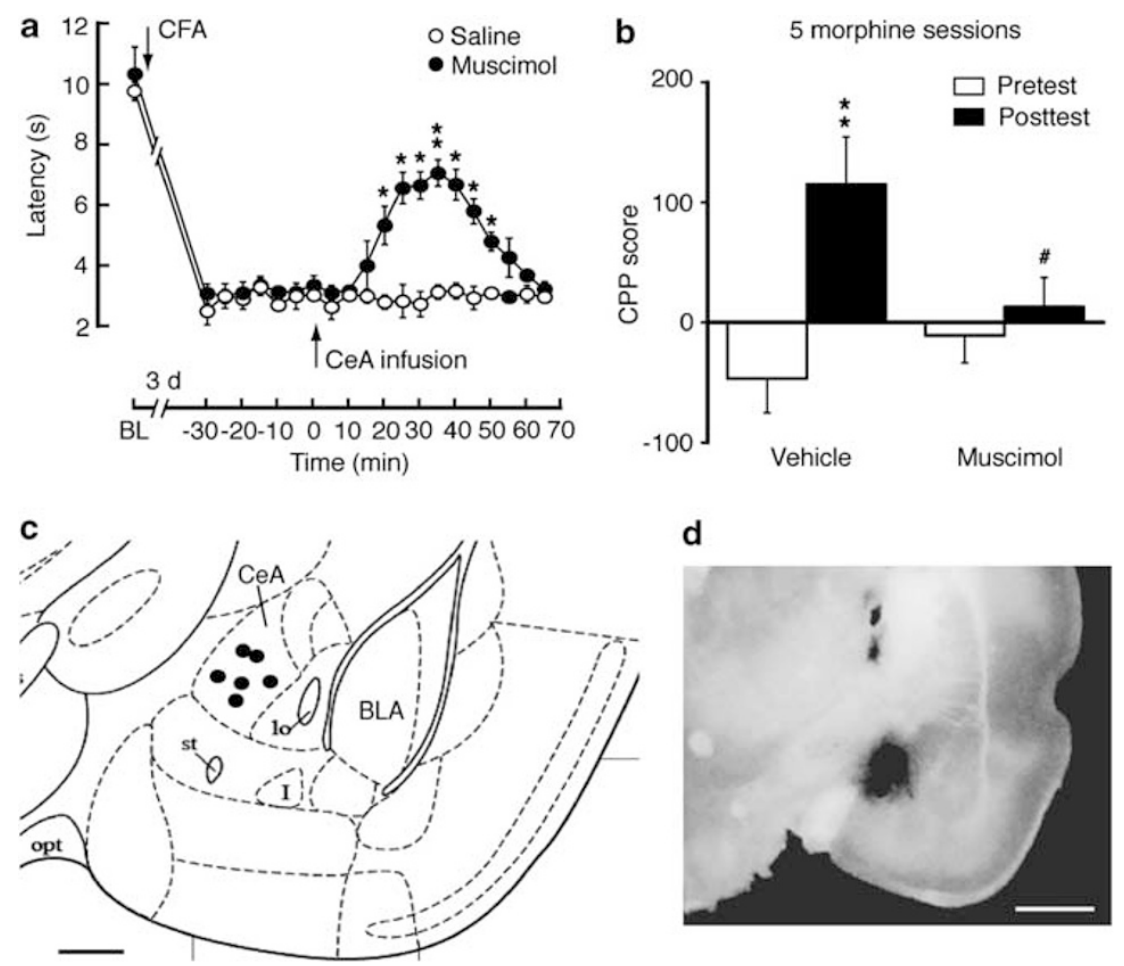

Figure 4 Activation of $\mathrm{CeA} G A B A_{A}$ receptors inhibits hyperalgesia and morphine reward. (a) Time course of pain threshold changes after intraplantar injection of CFA in rats with CeA infusion of saline or muscimol (two-way ANOVA, time, $F_{(20,200)}=61.04, p<0.0001$; muscimol, $F_{(I, 10)}=72.77$, $p<0.000$ I; time $\times$ muscimol, $F_{(20,200)}=11.35, p<0.000 I ; n=6$ each group). BL, baseline. (b) Preference behaviors after five sessions of morphine conditioning in naïve rats pretreated with CeA infusion of vehicle or muscimol (*preference comparison within group by paired $t$-test: vehicle, $t_{(1,10)}=5.596, p=0.0025$; muscimol, $t_{(1,10)}=1.003, p=0.3621 .{ }^{*}$ Comparison between groups by two-way ANOVA: time, $F_{(1,10)}=24.61, p=0.0006 ;$ muscimol, $F_{(1,10)}=0.7951$, $p=0.3935$; time $\times$ muscimol, $F_{(1,10)}=13.6 \mid, p=0.0042 ; n=6$ each group). (c, d) Schematic drawing depicting the position of cannula tips (dots) for muscimol microinfusions (c) and an image of brain slice showing the infusion site with a dye (d) within the CeA. Scale bars =0.5 mm (c) and I mm (d).

Both addictive opioids and chronic pain induce synaptic adaptations in the brain including $\mathrm{CeA}$, which are important for the development of corresponding behaviors (Bie et al, 2012; Luscher and Malenka, 2011; Neugebauer et al, 2004; Russo et al, 2010; Zhu et al, 2007). CeA consists of 95\% GABAergic neurons (Ehrlich et al, 2009; Haubensak et al, 2010). In rats with persistent inflammatory pain, we observed a significant decrease in GABA synaptic activity in CeA neurons, consistent with a previous report in a rat model of arthritic pain (Ren and Neugebauer, 2010). Activation of CeA $\mathrm{GABA}_{\mathrm{A}}$ receptors reduces CFA-induced hyperalgesia in rats, as shown in a previous report (Pedersen et al, 2007) and in the current study. CeA modulation of pain is mediated via its projections to the periaqueductal gray of the descending pain-modulating system (Bourgeais et al, 2001; Neugebauer et al, 2004). Our study further demonstrates that CPP-eliciting morphine, similar to pain, also reduces GABA synaptic activity. Whereas our analysis of mIPSCs indicates potential changes at both pre- and postsynaptic sites of GABA synapses, further studies with multidisciplinary approaches are necessary to identify pre- and postsynaptic mechanisms for the GABA reduction. It remains unknown how persistent pain and repeated opioids reduce GABA function in $\mathrm{CeA}$ neurons. In this regard, we have shown that persistent pain causes downregulation of glutamic acid decarboxylase 65 , a predominantly presynaptic GABA-synthesizing enzyme for GAGA release (Soghomonian and Martin, 1998; Tian et al, 1999), through an epigenetic mechanism of histone hypoacetylation, resulting in decreased GABA synaptic function (Zhang et al, 2011). Thus, it is possible that similar activity-dependent epigenetic mechanisms are involved in pain-induced reduction of GABA function in CeA neurons.

As part of the brain's reward system, CeA mediates the process of emotional learning of stimulus-reward association (Baxter and Murray, 2002) and the circuitry may involve CeA projections to neurons in the ventral tegmental area (VTA), as stimulation of CeA GABAergic fibers modulates activity of VTA dopaminergic neurons involved in opioid reinforcement (Everitt et al, 1999; Gonzales and Chesselet, 1990; Leshan et al, 2010). Our data of blocking and activating $\mathrm{CeA} \mathrm{GABA}_{\mathrm{A}}$ receptors on $\mathrm{CPP}$ behavior indicate that changes in CeA GABA synaptic function is sufficient to influence the behavior of opioid reward. It is noteworthy that home cage injection of morphine is ineffective on GABA function in CeA neurons, indicating that context-related discriminative learning of the rewarding effect of morphine during morphine paring with distinctive chambers may be required for the reduction in GABA synaptic function in CeA. Recent studies have shown that both CeA and the basolateral nucleus of the amygdala are critical in the process of contextual learning for acquisition and expression of positive effect (eg, drug 
a

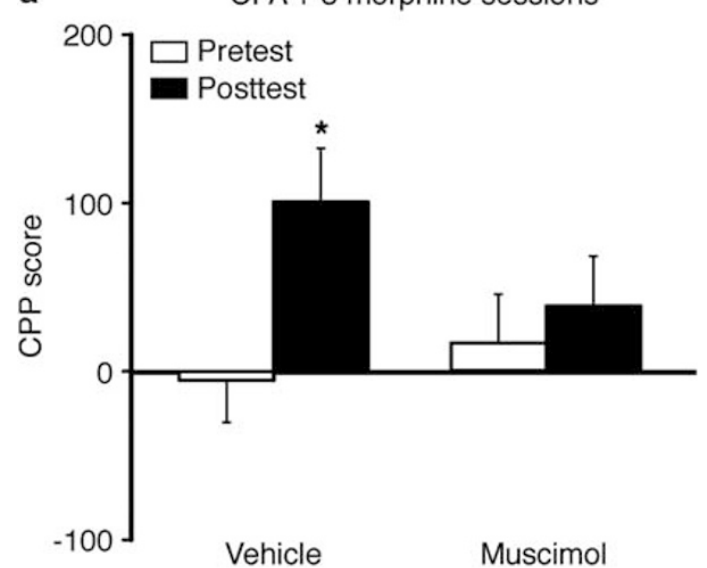

b

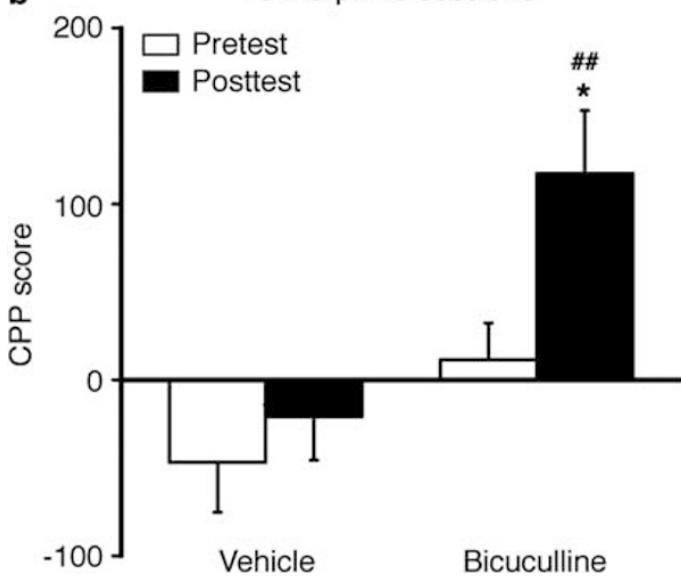

Figure $5 \mathrm{CeA} G A B A_{A}$ receptors mediate pain facilitation of morphine reward. (a) Preference behaviors after three sessions of morphine conditioning in CFA-injected rats pretreated with $\mathrm{CeA}$ infusion of vehicle or muscimol (*preference comparison within group by paired $t$-test: vehicle, $t_{(1,12)}=4.958, p=0.0228$; muscimol, $t_{(1,10)}=0.9728, p=0.3753$. Comparison between groups by two-way ANOVA: time, $F_{(I, I)}=16.95$, $p=0.0017$; muscimol, $F_{(1,1)}=0.2680, \quad p=0.6150$; time $\times$ muscimol, $\left.F_{(I, I)}=7.361, p=0.0202 ; n=6-7\right)$. (b) Preference behaviors after three sessions of morphine conditioning in naïve rats pretreated with $\mathrm{CeA}$ infusion of vehicle or bicuculline (*preference comparison within group by paired $t$-test: vehicle, $t_{(1,10)}=1.545, p=0.1829$; bicuculline, $t_{(1,10)}=3.414$, $p=0.0190$. " comparison between groups by two-way ANOVA: time, $F_{(1,10)}=13.97, p=0.0039$; bicuculline, $F_{(1,10)}=7.678, p=0.0198$; time $\times$ bicuculline, $F_{(I, 10)}=5.123, p=0.0471 ; n=6$ each group). ${ }^{\# \#} p<0.01$.

reward) as well as aversive responses of negative effect (eg, fear; Baxter and Murray, 2002; Maren et al, 2013; Murray, 2007; Wilensky et al, 2006). As shown in basolateral nucleus of the amygdala and hippocampal neurons, a common cellular mechanism for fear learning and memory is glutamate-mediated neuronal hyperexcitability induced by reduced GABAergic inhibitory function through disinhibition (Reger et al, 2012; Rodriguez Manzanares et al, 2005; Santos et al, 2013). A disinhibition mechanism of reduced GABA function also is responsible for the excitation of dopamine neurons in VTA in behaviors of context-reward association (Luo et al, 2011). Thus, it is possible that the reduced GABA function in CeA observed in this study may lead to hyperactivity of neurons in CeA-targeted brain areas such as VTA and hippocampus in the process of discriminative learning of morphine reward.

CPP behavior can be driven by motivational effects of drug reward and by removal of an aversive state such as opioid inhibition of aversive pain. Thus, pain relief is rewarding and analgesic agents can reliably induce CPP behavior in animal models of neuropathic and inflammatory pain (Fields, 2004; King et al, 2009; Sufka, 1994). Our results show that, when pain is acutely inhibited either before or after morphine-conditioning sessions, acquisition of morphine CPP is still facilitated in CFA-injected rats. This indicates that the facilitated CPP response we observed is due more to a heightened rewarding effect of morphine than to morphine inhibition of acute pain and potentially its associated aversion per se. However, morphine and indomethacin used in this study may have differential efficacies in pain inhibition and these experiments do not exclude contribution of rewarding effect from morphine inhibition of lasting emotional component of pain. As such, this heightened rewarding effect of morphine could be the result of interactive changes in the CeA circuitry mediating both drug reward and emotional pain, an issue that needs further investigation in future studies. Whereas this study focused on the initial acquisition rate for CPP behavior of opioid reward, previous studies examined pain effects on the magnitude of already acquired CPP behavior and established behavior of opioid intake with controversial results reported. Some studies showed that pain reduced opioid-induced CPP or opioid self-administration (Martin et al, 2007; Narita et al, 2005; Ozaki et al, 2003), but other studies found that pain enhanced opioid CPP and selfadministration (Cahill et al, 2013; Colpaert et al, 2001; Kupers and Gybels, 1995; Sufka, 1994). The reasons for the discrepancy are unclear and it appears likely that the pain effect on acquired behaviors of opioid reward is dependent on opioid doses used in different animal models of pain. Our current results show a pain-facilitated process of acquiring CPP behavior of morphine reward and a synaptic mechanism for pain-reward interaction that may be involved in the facilitated acquisition of preference behavior.

Clinically, the effect of chronic pain on the liability of opioid use and abuse has been a pressing issue, as nonmedical use of prescription opioids has dramatically increased in recent years, including incidences of misuse of prescription opioids for pain control (Compton and Volkow, 2006; Sullivan and Ferrell, 2005; Woolf and Hashmi, 2004). Compared with the general population, a smaller subpopulation of pain patients taking repeated opioids develop addiction to opioids, often with preexisting conditions (Ballantyne and LaForge, 2007; Hojsted and Sjogren, 2007). How pain affects the development of opioid addiction in patients and what are the underlying neurobiological mechanisms are still unknown. In clinical settings, many factors would influence behaviors of drug taking and an important such factor is the comorbid negative emotions such as depression and anxiety in chronic pain patients (Huyser and Parker, 1999; McWilliams et al, 2003; Wilson et al, 2001). Although negative mood of depression may inhibit drug abuse by counteracting positive emotion-associated drug reward, stressful stimuli can increase opioid-seeking behavior 
(Koob, 1999; Kreibich et al, 2009; Leknes and Tracey, 2008; $\mathrm{Lu}$ et al, 2003), suggesting that psychological dysfunction may differentially influence behavior of opioid intake and susceptibility to opioid abuse. However, such pain-associated emotional behaviors of negative effect have not been systemically characterized or consistently observed during the time frame of experiments in currently used animal models of chronic pain (Urban et al, 2011). In addition, pain may have differential effects on established behaviors of opioid seeking/intake and on acquisition of those behaviors. Although this study in a simpler experimental setting of animal models cannot directly model the much complex clinical situations, it provides original evidence indicating that pain may serve as one predisposing factor to facilitate acquisition responses to opioid reward through CeA-related learning and processing of opioid reward involving reduced GABA synaptic function and consequently neuronal disinhibition, a converged effect on CeA neurons by both pain and opioids.

\section{FUNDING AND DISCLOSURE}

The authors declare no conflict of interest.

\section{ACKNOWLEDGEMENTS}

This work was funded by the National Institute on Drug Abuse grants DA023069 and DA027541 to ZZP and by Development Program of Basic Research of China (2014CB548100) and National Natural Science Foundation of China (31100802 and 91332109) to ZZ.

\section{REFERENCES}

Ballantyne JC, LaForge KS (2007). Opioid dependence and addiction during opioid treatment of chronic pain. Pain 129: 235-255.

Banta-Green CJ, Von Korff M, Sullivan MD, Merrill JO, Doyle SR, Saunders K (2010). The prescribed opioids difficulties scale: a patient-centered assessment of problems and concerns. Clin J Pain 26: 489-497.

Baxter MG, Murray EA (2002). The amygdala and reward. Nat Rev Neurosci 3: 563-573.

Bhargava HN (1994). Diversity of agents that modify opioid tolerance, physical dependence, abstinence syndrome, and selfadministrative behavior. Pharmacol Rev 46: 293-324.

Bie B, Wang Y, Cai YQ, Zhang Z, Hou YY, Pan ZZ (2012). Upregulation of nerve growth factor in central amygdala increases sensitivity to opioid reward. Neuropsychopharmacol 37: 2780-2788.

Bie B, Zhu W, Pan ZZ (2009). Rewarding morphine-induced synaptic function of delta-opioid receptors on central glutamate synapses. J Pharmacol Exp Ther 329: 290-296.

Boscarino JA, Rukstalis M, Hoffman SN, Han JJ, Erlich PM, Gerhard GS et al (2010). Risk factors for drug dependence among out-patients on opioid therapy in a large US health-care system. Addiction 105: 1776-1782.

Bourgeais L, Gauriau C, Bernard JF (2001). Projections from the nociceptive area of the central nucleus of the amygdala to the forebrain: a PHA-L study in the rat. Eur J Neurosci 14: 229-255.

Cahill CM, Xue L, Grenier P, Magnussen C, Lecour S, Olmstead MC (2013). Changes in morphine reward in a model of neuropathic pain. Behav Pharmacol 24: 207-213.
Colpaert FC, Tarayre JP, Alliaga M, Bruins Slot LA, Attal N, Koek W (2001). Opiate self-administration as a measure of chronic nociceptive pain in arthritic rats. Pain 91: 33-45.

Compton WM, Volkow ND (2006). Major increases in opioid analgesic abuse in the United States: concerns and strategies. Drug Alcohol Depend 81: 103-107.

Edlund MJ, Martin BC, Fan MY, Devries A, Braden JB, Sullivan MD (2010). Risks for opioid abuse and dependence among recipients of chronic opioid therapy: results from the TROUP study. Drug Alcohol Depend 112: 90-98.

Ehrlich I, Humeau Y, Grenier F, Ciocchi S, Herry C, Luthi A (2009). Amygdala inhibitory circuits and the control of fear memory. Neuron 62: 757-771.

Everitt BJ, Parkinson JA, Olmstead MC, Arroyo M, Robledo P, Robbins TW (1999). Associative processes in addiction and reward. The role of amygdala-ventral striatal subsystems. Ann N Y Acad Sci 877: 412-438.

Fields HL (2004). State-dependent opioid control of pain. Nat Rev Neurosci 5: 565-575.

Fields HL (2000). Pain modulation: expectation, opioid analgesia and virtual pain. Prog Brain Res 122: 245-253.

Gonzales C, Chesselet MF (1990). Amygdalonigral pathway: an anterograde study in the rat with Phaseolus vulgaris leucoagglutinin (PHA-L). J Comp Neurol 297: 182-200.

Gottfried JA, O’Doherty J, Dolan RJ (2003). Encoding predictive reward value in human amygdala and orbitofrontal cortex. Science 301: 1104-1107.

Haubensak W, Kunwar PS, Cai H, Ciocchi S, Wall NR, Ponnusamy $\mathrm{R}$ et al (2010). Genetic dissection of an amygdala microcircuit that gates conditioned fear. Nature 468: 270-276.

Hojsted J, Sjogren P (2007). Addiction to opioids in chronic pain patients: a literature review. Eur J Pain 11: 490-518.

Huyser BA, Parker JC (1999). Negative affect and pain in arthritis. Rheum Dis Clin North Am 25: 105-121, vi.

Johnston IN, Milligan ED, Wieseler-Frank J, Frank MG, Zapata V, Campisi J et al (2004). A role for proinflammatory cytokines and fractalkine in analgesia, tolerance, and subsequent pain facilitation induced by chronic intrathecal morphine. J Neurosci 24: 7353-7365.

Kahan M, Srivastava A, Wilson L, Gourlay D, Midmer D (2006). Misuse of and dependence on opioids: study of chronic pain patients. Can Fam Physician 52: 1081-1087.

King T, Vera-Portocarrero L, Gutierrez T, Vanderah TW, Dussor $\mathrm{G}$, Lai J et al (2009). Unmasking the tonic-aversive state in neuropathic pain. Nat Neurosci 12: 1364-1366.

Koob GF (1999). Stress, corticotropin-releasing factor, and drug addiction. Ann N Y Acad Sci 897: 27-45.

Koob GF, Volkow ND (2010). Neurocircuitry of addiction. Neuropsychopharmacol 35: 217-238.

Kreibich AS, Briand L, Cleck JN, Ecke L, Rice KC, Blendy JA (2009). Stress-induced potentiation of cocaine reward: a role for CRF R1 and CREB. Neuropsychopharmacol 34: 2609-2617.

Kupers R, Gybels J (1995). The consumption of fentanyl is increased in rats with nociceptive but not with neuropathic pain. Pain 60: 137-141.

Le Merrer J, Becker JA, Befort K, Kieffer BL (2009). Reward processing by the opioid system in the brain. Physiol Rev 89: 1379-1412.

Leknes S, Tracey I (2008). A common neurobiology for pain and pleasure. Nat Rev Neurosci 9: 314-320.

Leshan RL, Opland DM, Louis GW, Leinninger GM, Patterson CM, Rhodes CJ et al (2010). Ventral tegmental area leptin receptor neurons specifically project to and regulate cocaine- and amphetamine-regulated transcript neurons of the extended central amygdala. J Neurosci 30: 5713-5723.

Lu L, Shepard JD, Hall FS, Shaham Y (2003). Effect of environmental stressors on opiate and psychostimulant reinforcement, reinstatement and discrimination in rats: a review. Neurosci Biobehav Rev 27: 457-491. 
Luo AH, Tahsili-Fahadan P, Wise RA, Lupica CR, Aston-Jones G (2011). Linking context with reward: a functional circuit from hippocampal CA3 to ventral tegmental area. Science 333: 353-357.

Luscher C, Malenka RC (2011). Drug-evoked synaptic plasticity in addiction: from molecular changes to circuit remodeling. Neuron 69: 650-663.

Maren S, Phan KL, Liberzon I (2013). The contextual brain: implications for fear conditioning, extinction and psychopathology. Nat Rev Neurosci 14: 417-428.

Martin TJ, Kim SA, Buechler NL, Porreca F, Eisenach JC (2007). Opioid self-administration in the nerve-injured rat: relevance of antiallodynic effects to drug consumption and effects of intrathecal analgesics. Anesthesiology 106: 312-322.

McCabe SE, Cranford JA, West BT (2008). Trends in prescription drug abuse and dependence, co-occurrence with other substance use disorders, and treatment utilization: results from two national surveys. Addict Behav 33: 1297-1305.

McDonald AJ (1982). Cytoarchitecture of the central amygdaloid nucleus of the rat. J Comp Neurol 208: 401-418.

McWilliams LA, Cox BJ, Enns MW (2003). Mood and anxiety disorders associated with chronic pain: an examination in a nationally representative sample. Pain 106: 127-133.

Murray EA (2007). The amygdala, reward and emotion. Trends Cogn Sci 11: 489-497.

Narita M, Kishimoto Y, Ise Y, Yajima Y, Misawa K, Suzuki T (2005). Direct evidence for the involvement of the mesolimbic kappa-opioid system in the morphine-induced rewarding effect under an inflammatory pain-like state. Neuropsychopharmacol 30: $111-118$.

Neugebauer V, Li W, Bird GC, Han JS (2004). The amygdala and persistent pain. Neuroscientist 10: 221-234.

Ozaki S, Narita M, Iino M, Miyoshi K, Suzuki T (2003). Suppression of the morphine-induced rewarding effect and G-protein activation in the lower midbrain following nerve injury in the mouse: involvement of G-protein-coupled receptor kinase 2. Neuroscience 116: 89-97.

Pedersen LH, Scheel-Kruger J, Blackburn-Munro G (2007). Amygdala GABA-A receptor involvement in mediating sensory-discriminative and affective-motivational pain responses in a rat model of peripheral nerve injury. Pain 127: 17-26.

Pohl M, Smith L (2012). Chronic pain and addiction: challenging co-occurring disorders. J Psychoactive Drugs 44: 119-124.

Reger ML, Poulos AM, Buen F, Giza CC, Hovda DA, Fanselow MS (2012). Concussive brain injury enhances fear learning and excitatory processes in the amygdala. Biol Psychiatry 71: 335-343.

Ren W, Neugebauer V (2010). Pain-related increase of excitatory transmission and decrease of inhibitory transmission in the central nucleus of the amygdala are mediated by mGluR1. Mol Pain 6: 93.
Rodriguez Manzanares PA, Isoardi NA, Carrer HF, Molina VA (2005). Previous stress facilitates fear memory, attenuates GABAergic inhibition, and increases synaptic plasticity in the rat basolateral amygdala. J Neurosci 25: 8725-8734.

Russo SJ, Dietz DM, Dumitriu D, Morrison JH, Malenka RC, Nestler EJ (2010). The addicted synapse: mechanisms of synaptic and structural plasticity in nucleus accumbens. Trends Neurosci 33: $267-276$

Santos M, D’Amico D, Spadoni O, Amador-Arjona A, Stork O, Dierssen M (2013). Hippocampal hyperexcitability underlies enhanced fear memories in TgNTRK3, a panic disorder mouse model. J Neurosci 33: 15259-15271.

Soghomonian JJ, Martin DL (1998). Two isoforms of glutamate decarboxylase: why? Trends Pharmacol Sci 19: 500-505.

Sufka KJ (1994). Conditioned place preference paradigm: a novel approach for analgesic drug assessment against chronic pain. Pain 58: 355-366.

Sullivan M, Ferrell B (2005). Ethical challenges in the management of chronic nonmalignant pain: negotiating through the cloud of doubt. J Pain 6: 2-9.

Tian N, Petersen C, Kash S, Baekkeskov S, Copenhagen D, Nicoll R (1999). The role of the synthetic enzyme GAD65 in the control of neuronal gamma-aminobutyric acid release. Proc Natl Acad Sci USA 96: 12911-12916.

Tzschentke TM (2007). Measuring reward with the conditioned place preference (CPP) paradigm: update of the last decade. Addict Biol 12: 227-462.

Urban R, Scherrer G, Goulding EH, Tecott LH, Basbaum AI (2011). Behavioral indices of ongoing pain are largely unchanged in male mice with tissue or nerve injury-induced mechanical hypersensitivity. Pain 152: 990-1000.

Wilensky AE, Schafe GE, Kristensen MP, LeDoux JE (2006). Rethinking the fear circuit: the central nucleus of the amygdala is required for the acquisition, consolidation, and expression of Pavlovian fear conditioning. J Neurosci 26: 12387-12396.

Wilson KG, Mikail SF, D'Eon JL, Minns JE (2001). Alternative diagnostic criteria for major depressive disorder in patients with chronic pain. Pain 91: 227-234.

Woolf CJ, Hashmi M (2004). Use and abuse of opioid analgesics: potential methods to prevent and deter non-medical consumption of prescription opioids. Curr Opin Investig Drugs 5: 61-66.

Zhang Z, Cai YQ, Zou F, Bie B, Pan ZZ (2011). Epigenetic suppression of GAD65 expression mediates persistent pain. Nat Med 17: 1448-1455.

Zhang Z, Pan ZZ (2012). Signaling cascades for delta-opioid receptor-mediated inhibition of GABA synaptic transmission and behavioral antinociception. Mol Pharmacol 81: 375-383.

Zhu W, Bie B, Pan ZZ (2007). Involvement of non-NMDA glutamate receptors in central amygdala in synaptic actions of ethanol and ethanol-induced reward behavior. J Neurosci 27: 289-298. 